\title{
Reconceituação do Serviço
Social: processo e movimento
da Escuela de Trabajo Social
da Universidade Católica de
Valparaíso*
}

Reconceptualization of Social Work: process and movement of Catholic University of Valparaiso's "Escuela de Trabajo Social"

Vicente de Paula Faleiros**

\begin{abstract}
Resumo - Este artigo de micro-história reflexiva refere-se à história da mudança do paradigma do Serviço Social funcionalista no processo de reconceituação vivido na Escola de Trabalho Social da Universidade Católica de Valparaíso, no Chile, de 1970 a 1973. Tem por objetivo discutir a fundamentação e a prática do paradigma reconceituado no contexto da experiência chilena de transição para o socialismo com liberdade e da articulação com o marxismo. O relato histórico tem como referência a escrita de uma micro-história na perspectiva de uma análise da totalidade, com base em narrativa pessoal e em documentos da época, conforme sugere Burke (1992), numa perspectiva da sociologia reflexiva (MELUCCI, 2005). A discussão da experiência aponta para a construção de uma articulação do Serviço Social com a ação política comprometida com a transformação das relações de dominação.

Palavras-chave: Reconceituação do Serviço Social; Funcionalismo; Dialética; Experiência Chilena.
\end{abstract}

\begin{abstract}
This reflective microhistory article refers to the history of the paradigm shift of the functionalist social service in the process of reconceptualization lived in the Social Work School of the Catholic University of Valparaíso - Chile from 1970 to 1973. Its purpose is to discuss the fundaments and the practice of the paradigm reconceptualized in the context of the Chilean experience of transition to socialism with freedom and this articulation with Marxism. The historical account has as reference the writing of a microhistory in the perspective of an analysis of the totality, based on personal narrative and documents of the time, as suggested by Burke (1992), from a perspective of reflective sociology (MELUCCI, 2005). The discussion of experience points to the construction of an articulation of social work with political action committed to the transformation of relations of domination.

Keywords: Social Work Reconceptualization; Functionalism; Dialectics; Chilean experience.
\end{abstract}

\footnotetext{
* O texto foi inspirado em palestra proferida na Universidade do Estado do Rio de Janeiro (Uerj) em novembro de 2017.

** Pós-doutorados pela Escola de Altos Estudos em Ciências Sociais (EHESS) - Paris (1991) e Université de Montréal (1996). Professor emérito da Universidade de Brasília. Docente na Pós-Graduação em Gerontotologia e na Graduação e Pós-graduação em Psicologia da Universidade Católica de Brasília. Correspondência: QS 7 LT 01 - Águas Claras, Brasília - DF. CEP: 71966-700. Email: <vicentefaleiros@terra.com.br>.
} 


\section{A experiência chilena de transição ao socialismo}

A história passada, vista do presente, é fundamental para ressignificar, no contexto atual, um fenômeno ou um acontecimento situado em outro contexto. Comparar contextos não é o objetivo deste artigo, mas sim discutir uma prática historicamente situada em outro momento do capitalismo latino-americano e da contra-hegemonia na área específica do Serviço Social na América Latina. Burke (1992) lembra que a história se interessa por toda a atividade humana, e no estudo em pauta é a história de uma expressão particular de um movimento latinoamericano do Serviço Social no século XX.

Embora o capitalismo mantenha sua estrutura de exploração, existem mudanças que se produzem na organização dessa mesma estrutura e também na superestrutura, na dialética da relação estrutura/história, como propõe Mészáros (2011). Nessa dialética se expressam as relações estruturais do capitalismo com os movimentos sociais e políticos, bem como os processos particulares de conservação e de mudança numa determinada sociedade.

A experiência chilena de 1970 a 1973, sob o governo de Salvador Allende, foi denominada de transição ao socialismo (BASSO et al., 1972). Essa transição, por via democrática, fez emergir um movimento de ruptura com o capitalismo periférico, um Estado dependente dos Estados Unidos, num aprofundamento da democracia de participação popular e de mudança do Estado, visando estar a serviço das camadas populares. A mudança da superestrutura política, a partir de um bloco de união de partidos, chamado de Unidade Popular (UP), com agrupação dos partidos socialista, comunista, radical e democratas cristãos de esquerda, provocou fortes reações na direita conservadora, principalmente nos grupos da Democracia Cristã, do Partido Nacional, da Direita Radical (PDR) e de grupos paramilitares, como Pátria e Liberdade.

Nesse processo, a UP representava a contraposição à dominação elitista, sendo uma união política das esquerdas, ou seja, uma fissura na hegemonia da classe dominante. A mobilização política e popular trouxe um fortalecimento para a organização sindical e para a organização populacional, com ocupação de terrenos nas cidades e um movimento fortíssimo pela reforma agrária.

O conflito de classes se expressou na luta política entre os adeptos da UP e partidos da direita, defensores da ordem dominante capitalista, culminando na adesão das forças armadas ao golpe de 11 de setembro de 1973. A partir daí, implantou-se uma das mais sangrentas ditaduras da América Latina, com o apoio dos Estados Unidos. Contabiliza-se em torno de seis mil mortos, além de inúmeras pessoas torturadas e exiladas.

Entretanto, no período da UP, novas formas de mobilização popular foram se construindo à medida que o boicote e a oposição das forças conservadoras se manifestavam e impediam o avanço do processo de de- 


\section{ReVistg all pavtg}

\} RECONCEITUAÇÃO DO SERVIÇO SOCIAL - FALEIROS, V.P. \}

DOI: $10.12957 /$ REP.2017.32723

mocratização popular. Várias empresas foram paralisadas pelos patrões e ocupadas pelos trabalhadores, num processo de produção coletiva. O boicote da distribuição de alimentos para a população fez emergir grupos locais para repasse de alimentos básicos organizados em Juntas de Abastecimento e Preços (JAPs). As JAPs geriam cotas de alimentos, conforme o território, principalmente de alguns cereais, leite em pó, óleo de cozinha e açúcar. Além disso, os caminhoneiros, desde o início de 1973, realizaram paralisações, financiadas, inclusive, pela ITT e CIA. As multinacionais boicotavam as peças de reposição para veículos e máquinas, desenvolvendose, em contraponto, formas de reutilização de peças e de produção substitutiva.

O processo de mobilização popular no Chile foi também uma reação à crise do capitalismo e do governo Eduardo Frei, deixando o país dividido entre as forças de mudança lideradas pela UP e as forças da direita ligadas ao Partido Nacional e à direita da Democracia Cristã. As posições se tornaram muito frontais, pois disputava-se fervorosamente a favor e contra a Unidade Popular, muitas vezes na própria família.

A Democracia Cristã se dividiu e sua ala mais à esquerda formou o Movimento de Ação Popular Unificado (Mapu). O bloco centrista apoiou o democrata cristão Radomiro Tomich; a direita da DC ficou com Frei. O conservadorismo era apoiado pelo jornal El Mercúrio, de propriedade da família Edwards, que havia dominado a produção do salitre. Eles foram responsáveis por provocar a guerra contra a Bolívia, uma vez que a saída para o Pacífico pela Bolívia implicava a ocupação das minas de salitre, e os Edwards a mantiveram fechada.

Essa conjuntura chilena era diferente da do Brasil. Após o golpe de 1964, agudizado em 1968 pelo Ato Institucional n 5, implantou-se o terror de Estado, institucionalizando a governança pela tortura. Ou seja, usou-se o terror como política, quer dizer, de modo a não haver espaço para o conflito, a democracia, a divergência (FALEIROS, 2010).

No Chile, durante o governo da Unidade Popular, o Estado implementou uma reforma agrária para os trabalhadores do campo e apoiou os cordões industriais por setor ou localização, com o apoio dos sindicatos, no sentido de fazer fluir a produção e romper o boicote. Além disso, também ampliou a economia mista, fortaleceu o monopólio do cobre e melhorou o acesso à saúde pública. A reforma agrária já vinha do processo implantado por Eduardo Frei, mas no governo de Allende houve um avanço com a desapropriação das grandes fazendas para distribuição de terras aos camponeses. Entretanto, os grandes proprietários passaram a também boicotar Allende, por exemplo, retirando as vacas do Chile e levando-as para a Argentina, de modo a promover a falta de carne para o povo chileno, agudizando a resistência da classe dominante à Unidade Popular.

No contexto internacional da época, a experiência chilena representou uma mudança na ordem dominante de divisão bipolar do mundo 


\section{hevistg all pgutg}

\} RECONCEITUAÇÃO DO SERVIÇO SOCIAL - FALEIROS, V. P. \}

DOI: $10.12957 /$ REP.2017.32723

nas áreas de influência dos Estados Unidos e da União Soviética. A América Latina se configurava como uma zona de influência norte-americana, denominada então de quintal dos Estados Unidos. A política exterior desse país não aceitava uma repetição da Revolução Cubana e articulou toda a sua força para impedir uma transição ao socialismo na sua área de influência. Nesse contexto, a União Soviética e Cuba apoiaram a experiência chilena de diversas formas, enviando alimentos, peças de reposição e propiciando intercâmbio político. No entanto, o Chile permaneceu independente do bloco soviético. Havia também divergências entre comunistas e socialistas; os primeiros, com a perspectiva de uma ênfase na produção, e os segundos, na revolução.

Os anos de 1970, no contexto do capitalismo, representam um momento de maior influência do Estado na economia, pois durante a crise do petróleo buscou-se apoiar a implantação de novas tecnologias para os combustíveis. Na França, a planificação foi desenvolvida e na América Latina foi apoiada com a criação da Comissão Econômica para a América Latina (Cepal). A ideia da planificação foi muito importante, aparecendo nos congressos de Serviço Social e no processo de desenvolvimento de comunidade com o apoio estatal. Exemplo disso foi o Congresso do Serviço Social Mundial de 1962, no qual se defendeu a ideia da planificação na relação do Serviço Social com o Estado.

No Chile, em 1970, a luta política era aberta, diferentemente do Brasil, onde havia ditadura desde 1964. Em outros países da América Latina também se havia implantado a ditadura, como no Uruguai, na Bolívia, no Peru e, mais tarde, na Argentina. No Chile, a nacionalização do cobre feita por Allende foi mantida por Pinochet, o que propiciou uma renda nacional que permitiu assegurar os privilégios dos militares na ditadura. Isso porque, ao manter o estado de guerra, os militares ganhavam em dobro, garantindose sua lealdade.

Durante o governo de Allende, além do boicote da carne e do boicote de reposição de peças, houve também o boicote de alimentos no comércio varejista, em manobra orquestrada pelos Estados Unidos para assegurar sua hegemonia.

O golpe de Estado no Chile, em 1973, foi uma guerra contra a intervenção do Estado, a experiência de transição ao socialismo e o modelo econômico de economia mista, com prisão dos militantes e esfacelamento das organizações de esquerda. A intenção era a implantação cruel e brutal de um modelo neoliberal, inspirado na Escola de Chicago, na ótica do Consenso de Washington. Augusto Pinochet, comandante do Exército, foi o líder do golpe de Estado contra Allende, figurando como traidor, pois havia se comprometido com a defesa da democracia. Allende sempre buscou resolver os conflitos por meio parlamentar, eleitoral e de consulta popular. Pinochet, por sua vez, boicotou um plebiscito previsto por Allende e o golpe de 11 de setembro impediu sua realização. 


\section{ReVistg aII PaUtg}

\} RECONCEITUAÇÃO DO SERVIÇO SOCIAL - FALEIROS, V.P. \}

DOI: $10.12957 /$ REP.2017.32723

Desde que Allende ganhou a eleição, em 1970, foi organizada a sedição, por exemplo, com o assassinato do General Schneider, que era Comandante do Exército. Allende teve que enfrentar a sedição da elite, da burguesia, que foi intensificada com a sedição militar. Um golpe de estado não é construído de uma hora pra outra. Implica a mobilização da opinião pública, junto com a mobilização política, com o desgaste econômico e a intervenção armada.

Allende detinha uma habilidade política extraordinária, afirmando que iria continuar na democracia até o último dia de seu governo. Assim, toda a vida social e política no Chile, de 1970 a 1973, foi um embate constante entre as forças hegemônicas e um processo contra-hegemônico.

Depois da volta da democracia, em 1990, a Comissão da Verdade contabilizou seis mil mortos e desaparecidos durante a ditadura, com pessoas torturadas em campos de concentração ou unidades das Forças Armadas e mesmo no Estádio Nacional. A minha prisão está relatada em um texto publicado pelo Conselho Federal de Psicologia (FALEIROS, 2011).

\section{Movimento de Reconceituação na Escuela de Trabajo Social da Universidade Católica de Valparaíso (UCV), em 1970}

A seguir, apresento o processo e o resultado da Reconceituação do Serviço Social na Escuela de Trabajo Social da Universidade Católica de Valparaíso, durante o governo da Unidade Popular, no sentido de repensar, no presente, um processo complexo para ressignificar o Movimento de Reconceituação em suas reflexões atuais. Nesse sentido, pode-se parafrasear a expressão de Marx no Dezoito Brumário: "os homens fazem a história nas condições dadas pelo passado", reinterpretando-a, ao dizer que nós fazemos a memória nas condições dadas pelo presente. Essa memória aqui apresentada não pretende reproduzir o passado, mas reinterpretá-lo.

No contexto latino-americano, o Serviço Social também foi se posicionando de forma mais ou menos explícita por uma transformação da sociedade ou pela defesa da ordem dominante (FALEIROS, 1982, 2016).

Nesse processo histórico, denominado de transição ao socialismo, minha vida pessoal no Chile confundia-se com a vida política e a participação de estudantes e professores da Universidade Católica de Valparaíso, imiscuindo-se na busca cotidiana pelo fortalecimento das lutas e das organizações populares, por exemplo, a dos cordões industriais, das Juntas de Abastecimento de Preços, dos sindicatos, das associações de moradores e das ocupações pela reforma agrária. As ocupações urbanas por movimentos políticos mais à esquerda da Unidade Popular, como o Movimiento de Izquierda Revolucionário (MIR), buscaram organizar novas formas de aglutinação comunitária e de justiça popular, como tribunais populares. Vários estudantes participavam dessas ocupações. Desse modo, essas práticas, como 


\section{hevistg all pgutg}

\} RECONCEITUAÇÃO DO SERVIÇO SOCIAL - FALEIROS, V. P. \}

DOI: $10.12957 /$ REP.2017.32723

reforma agrária, cordões industriais, implantação de serviços nas fábricas nacionalizadas e mudanças nos serviços de saúde, tornaram-se campos de estágio para vinculação do Serviço Social às lutas populares.

A construção da Escuela de Trabajo Social da Universidade Católica de Valparaíso foi um projeto político de mudança de concepção, de organização curricular, de compromisso com as lutas populares, de crítica radical ao funcionalismo e de vinculação com o marxismo. Nesse sentido, houve uma busca no sentido de repensar e de refazer o modelo tradicional do Serviço Social, principalmente no que se refere ao seu vínculo para manter a ordem dominante, com o exercício da sua função ideológica de autojustificativa e de sua prática clientelista do favor.

A discussão de um Serviço Social revolucionário implicava uma mudança de aliança, de compromisso com as lutas populares. Para isso, era necessário fundamentar-se na teoria marxista da contradição e da totalidade a partir de uma prática teórica reflexiva e sistemática, que também assinalava o questionamento de uma forma de ação tradicional. No prefácio do Projeto de Escola de Trabalho Social da UCV (PALMA et al., 1972¹) assinala-se que se trata de uma opção por inserir-se na realidade das lutas populares, de um compromisso com uma ação transformadora no marco da totalidade. Os conceitos de totalidade e contradição passaram a ser a base da construção desse projeto, que se ancorava na análise da realidade.

Essa concepção não surgiu de um grupo isolado de intelectuais, mas de um processo de crise da sociedade, do Serviço Social e da própria dinâmica de conflitos na Universidade Católica de Valparaíso. Com efeito, desde 1966 havia uma crise nas escolas de Serviço Social e de Educação Familiar. Por sua vez, em 1967 começa a luta pela reforma universitária e, em 1968, produz-se um autoquestionamento de ambas as escolas citadas. Em 1969 forma-se uma comissão mista de docentes e alunos para repensar ambas as profissões. Em 1970 agudiza-se a crise na Escola de Serviço Social e os estudantes exigem qualificação do pessoal docente e uma reformulação total e radical da profissão.

Quando cheguei, exilado, em 1970, para trabalhar na UCV a partir de um convite, havia greve de estudantes para a reformulação do pessoal docente, instituindo-se uma comissão de professores e estudantes, da qual passei a fazer parte. Ela se destinava a repensar o Serviço Social juntamente com a Educação Familiar, a partir da pressão estudantil para uma mudança radical de ambas as profissões. Os líderes estudantis faziam parte dos partidos políticos de esquerda.

A reitoria da UCV, exercida por Raúl Allard, da ala progressista da Democracia Cristã, apoiou o processo de democratização da universidade e de mudanças no Serviço Social. A própria universidade tinha uma assem-

\footnotetext{
${ }^{1}$ Fizeram parte da Comissão Organizadora da Esculea de Trabajo Social e da autoria do Projeto de Reformulacão: Eloisa Pizarro de Palma, Maria Edith Jofre, Vicente de Paula Faleiros, Teresa Quiroz e Cecilia Paiva.
} 


\section{ReVistg all pavtg}

\} RECONCEITUAÇÃO DO SERVIÇO SOCIAL - FALEIROS, V.P. \}

DOI: $10.12957 /$ REP.2017.32723

bleia anual de alunos e professores, chamada de Claustro Pleno, que discutia toda a estrutura universitária, com comissões, debates e votações. Também fizemos uma série de debates e assembleias com os estudantes e professores de ambas as escolas.

O primeiro ato da discussão dessas duas escolas foi uma imersão na história do Chile, com destaque para o processo de dependência e dominação em articulação com a transformação. Do ponto de vista marxista, tratava-se de partir da relação abstrato-concreto-abstrato para se entender a história e suas dimensões de totalidade, bem como do Serviço Social nesse processo. Repensar o Serviço Social implicava pensá-lo na realidade histórica e na realidade em movimento, na dinâmica de mobilização então vivida. Dentre os autores estudados destacam-se Garreton, Hinkelamert, Faletto e Cardoso, Vuskovic, Theotônio dos Santos, Quijano, Gunder Frank, Caputo e Pizarro, dentre outros.

Via-se que a própria história do Chile não era apropriada pela classe trabalhadora, nem mesmo a história do movimento operário, que era somente conhecida pelos dirigentes e líderes das centrais sindicais. Era fundamental desconstruir o processo de alienação ao qual é levada a classe trabalhadora pela ideologia dominante.

A fundamentação do Projeto da Escuela de Trabajo Social da UCV partia do pressuposto da crítica, questão central da leitura e da interpretação da história, buscando uma forma de dar relevo à perspectiva das classes dominadas. Um dos eixos centrais do novo currículo passou a ser a história do Chile, havendo um bloco de cinco disciplinas denominadas de "Realidade Nacional", nas quais se abordavam as dimensões relacionadas ao processo de formação histórica do país e de suas especificidades conjunturais e temáticas, por exemplo, a realidade do campo, da cidade e da relação industrial.

A leitura da história sofreu uma mudança em sua forma, revertendo a perspectiva dos dominantes para se ver a história na perspectiva dos dominados. Deixou-se, inclusive, de considerar a classe trabalhadora como parte marginalizada da sociedade, passando-se a enxergá-la como protagonista da transformação. Fez-se uma crítica da teoria da marginalidade, buscando tornar objeto do Serviço Social a práxis da classe trabalhadora. Nesse sentido, o Projeto da Escuela de Trabajo Social da UCV parte da dialética da relação da totalidade com as suas contradições e da práxis de transformação, numa crítica da "ação dominadora" em oposição à "ação liberadora".

É nesse sentido que se propõe, como objetivo da ação liberadora, a transformação da relação opressor-oprimido vinculada à dialética da situação e da organização coletiva no contexto. No referido projeto, concebe-se a liberação como um processo de organização popular, de gestão popular, de mobilização popular, de politização, de conscientização e de participação. Dessa maneira, aliam-se estratégias, táticas e operações nas condições concretas com um procedimento técnico adequado e construído conjuntamente com as pessoas participantes. 


\section{hevistg all pgutg}

\} RECONCEITUAÇÃO DO SERVIÇO SOCIAL - FALEIROS, V. P. \}

DOI: $10.12957 /$ REP.2017.32723

Algumas interpretações desses objetivos fizeram com que se entendesse a organização e a mobilização como propostas de uma vanguarda ou de um grupo detentor da consciência crítica. Entretanto, esse não foi o propósito do projeto em discussão, pois ele foi concebido e praticado sempre articulado ao movimento histórico e às forças em presença. Desse modo, esse processo pode ser realizado tanto pela ação coletiva, quanto por instituições, embora seja necessário levar em conta as condições em que se realiza.

Os grupos sociais aos quais se estava dirigindo o Serviço Social deixaram de corresponder à definição funcional de marginalizados. Fizemos uma crítica à teoria da marginalidade, que dominava as análises, para incorporar novas formas de consciência e de ação na situação em que se vivia. À consciência passiva propunha-se desenvolver uma consciência protagonizada, numa visão conflituosa da sociedade, aprofundando-se a teoria da conscientização proposta por Paulo Freire, em seu livro Pedagogia do Oprimido (1970)

Nesse sentido, em oposição à teoria do consenso, adotou-se abertamente a teoria do conflito. Nessa sociabilidade conflituosa, não se viam os sujeitos do Serviço Social como necessitados de benefícios, mas como protagonistas de uma transformação. A ideia de protagonismo social das classes trabalhadoras é crucial na formulação do projeto e na sua execução.

A proposta da Escuela de Trabajo Social da UCV coloca em discussão o objeto e os objetivos do Trabalho Social, considerando os campos de ação e a metodologia numa perspectiva de transformação da sociedade capitalista. Nesse sentido, elabora uma nova epistemologia da construção do objeto, que se descola da solução de problemas isolados para se tornar uma questão da realidade em movimento. Desta forma, desconstrói o objeto do fazer profissional tradicional e focalista, a partir da situação-problema, com ação circunstancial de assistência, orientação ao desvalido, ao assistido, ao pobre, através de trabalho com casos, grupos e comunidades.

A epistemologia de construção do objeto do Serviço Social na Escuela parte de uma análise articulada e dialética da relação da teoria com a história, considerando as análises do contexto global e das contradições reais e concretas da sociedade. No entanto, o objeto não se elabora com pressupostos abstratos, genéricos, provenientes de uma visão da estrutura do capitalismo. Essa epistemologia pressupõe o sujeito em ação, em relações que se põem em cada situação, levando-se em consideração a história de lutas e de conflitos com o poder dominante, social e institucional, conforme a práxis do dominado, nas condições concretas de relação com a mobilização, organização e projetos de liberação.

Nos estágios da Escuela, a ênfase era dada na relação entre a ação e as condições da ação; do contrário, cair-se-ia no voluntarismo ou no determinismo. Se se considerasse só a prática sem as condições, ou somente as condições sem a prática, seria descartado o processo dialético da própria 


\section{ReVistg all pavtg}

\} RECONCEITUAÇÃO DO SERVIÇO SOCIAL - FALEIROS, V.P. \}

DOI: $10.12957 /$ REP.2017.32723

realidade. Desse modo, via-se a organização popular como uma mediação, e não um fim em si mesmo; mediação para fortalecer o poder dos dominados, como na discussão da gestão popular, no sentido de fortalecer a autogestão, referindo-se também ao dia a dia.

A capacitação popular (hoje melhor denominada de formação) colocava os trabalhadores sociais como educadores sociais numa práxis de compromisso com a mudança do cotidiano, na configuração da vida material. A politização discutia as relações em que o próprio dominado procura entender o sentido no qual quer orientar a mudança, buscando o trabalho social para apoiar a discussão de alternativas, sem, contudo, impor uma visão dogmática da sociedade capitalista ou de uma sociedade socialista para projetar relações menos desiguais.

Nesse sentido, a conscientização se tornava um processo de análise dos limites do sistema, como assinala o referido Projeto (PALMA et al. 1972) na página 45: "dándose cuenta de las situaciones límites y proyectando nuevas situaciones para objetivar una cultura y una sociedad cada vez más autónoma en la que se hace sujeto", participante da mudança. Assim, baseava-se na teoria de Marx (2007) ao considerar que o educador precisa ser educado em circunstâncias que devem ser analisadas, pois a práxis é um processo que implica todos os aspectos da vida humana e todos os homens. Esses objetivos não eram considerados de forma sequencial, mas dialeticamente, na transformação das condições concretas, com apoio de ação técnica numa articulação estratégica e tática.

O projeto da Escuela previa campos de ação, com fundamento no protagonismo da mobilização pela transformação, e não numa previsão idealista. Na realidade chilena, os sujeitos protagonistas da transformação eram a classe operária, os sindicatos, o movimento camponês pela reforma agrária e os movimentos urbanos. Os campos de estágio e de ação foram articulados nessa lógica do protagonismo, incluindo as organizações específicas pelos direitos sociais da saúde e da previdência.

Dentro das empresas estatizadas, algumas abandonadas pelos patrões, era fundamental propiciar e organizar serviços sociais no interesse dos trabalhadores, como creches, acesso aos direitos, condições laborais, de saúde, de informação e formas de gestão participativa, entre outros. Cabe ressaltar que essa experiência de gestão foi relatada num texto de Ademar Sato, em um depoimento feito numa pesquisa que coordenei sobre planejamento estratégico democrático em 1998 (IDR, 1998).

Os grupos populares urbanos eram muito diversificados, mobilizando-se por habitação, saúde, creches etc. Os estágios faziam também a mediação nas instituições que aceitavam os estudantes. O campo de ação vinculado ao movimento camponês dava oportunidade de participar dos assentamentos de reforma agrária, com ênfase na educação social, na organização de serviços, do cotidiano e na mobilização. As instituições de reforma agrária apoiavam esse trabalho. 


\section{hevistg all pgutg}

\} RECONCEITUAÇÃO DO SERVIÇO SOCIAL - FALEIROS, V. P. \}

DOI: $10.12957 /$ REP.2017.32723

Como o Estado dirigido pela Unidade Popular estava em conflito com a direita, a própria política social servia para fortalecer a organização popular e melhorar as condições de vida. No momento, não se percebeu, no calor do processo, que o Estado não seria sempre um aliado permanente dos trabalhadores. Apesar disso, havia a crença de que a Unidade Popular dava as condições superestruturais para uma mudança da relação do Estado com as classes trabalhadoras, favorecendo-as. Embora muitos serviços ainda continuassem precários e insuficientes para a população, conforme mencionado no referido projeto (PALMA, et al., 1972, p. 54), "el trabajo social necesita ubicarse criticamente en las políticas sociales gubernamentales".

Faleiros (1981) caracteriza essa proposta da Escuela como revolucionária, na crítica ao funcionalismo, ao clientelismo e, principalmente, ao processo de dominação e sujeição definidos pelo Serviço Social então hegemônico. Na formulação da metodologia fez-se uma crítica ao positivismo, além do funcionalismo, no sentido de romper com a visão da harmonia social e da vinculação aos valores da integração dos dominados à ordem dominante.

Uma das questões fundamentais da metodologia era considerar a relação dialética entre teoria e prática, como mencionado na página 59 do Projeto ( PALMA et al. 1972): "La acción social implica teoría y práctica", considerando-se as teorias científicas numa perspectiva ao mesmo tempo heurística e sistematizadora do desenvolvimento do conhecimento e abertas à crítica, possuindo uma relação dialética interna em constante comunicação com a prática e a história. Essa profunda relação com a história coloca o conhecimento na busca permanente pela transformação dos seres humanos e da sociedade. Desse modo, essa construção epistemológica pressupunha, segundo o projeto da Escuela, um movimento, uma relação entre a observação sensível e a elaboração racional, sem estabelecer etapas entre elas, como mais tarde foram definidas por Lima (1974).

No projeto em análise fala-se de aproximações ao objeto e à realidade, considerando-se o todo em movimento, na perspectiva proposta por Kosik (1967). O diálogo com as formulações das propostas metodológicas em efervescência na América Latina de então foi levado em consideração, como, por exemplo, com as proposições de Zabala $(1974)^{2}$. Em 1976, o Celats discutiu amplamente a questão da metodologia, sistematizada num texto de Maria Cristina Salazar (1976), em que ela critica a prática como produtora absoluta de teoria, elaborando também uma crítica ao Estado e colocando a questão da diversidade das ações do Serviço Social. A autora salienta, ainda, a dificuldade de produção de uma teoria dialética a partir dessa prática.

No Projeto da Escuela da UCV (PALMA et al. 1972), na página 62 , considera-se que a metodologia "comprende un proceso y una estructura.

${ }^{2}$ Juan Mojica, vindo da Colômbia, também colaborou com o projeto da Escuela da UCV. 


\section{ReVistg all pavtg}

\} RECONCEITUAÇÃO DO SERVIÇO SOCIAL - FALEIROS, V.P. \}

DOI: $10.12957 /$ REP.2017.32723

Como proceso es un movimiento que no se agota o detiene en un solo momento, sino que posee una dinamicidad histórica. Como estructura exige una ordenación en términos de teoría y mediación que permita sistematizar y actuar". Desta forma, a estrutura não se desvincula do processo e nem se reduz a um somatório de tecnologias ou conjunto de fórmulas. Para mudar a realidade, portanto, é preciso articular as mediações do que é dado como fenômeno com o que é construído como interpretação e proposta no movimento entre o que se apresenta como essencial e como imediato.

Para ilustrar, um exemplo prático: na empresa do Porto de Valparaíso houve a prática de estágio, articulando-se a relação entre o sindicato, a direção da empresa, alguns assistentes sociais que aderiram ao projeto e o serviço de saúde. A questão era o alcoolismo no Porto de Valparaíso, questão realmente complexa e difícil, pois a região era exportadora de vinho, de modo que se podia obtê-lo facilmente com perfurações nos barris. A aproximação com essa realidade, após contato com as assistentes sociais da empresa, que em parte aceitou a proposta, foi feita com a inserção de docentes, assistentes sociais concordantes e estagiários no próprio cais, em conversas diretas com os operários.

No diário de campo anotamos que havia muitas narrativas dos trabalhadores. Ao observarmos faltas ao trabalho nas segundas-feiras, verificamos o alcoolismo nos fins de semana. Assim, aproximamo-nos do serviço de saúde da empresa e, em seguida, propusemos um trabalho conjunto com o serviço médico, os dependentes do álcool, o sindicato e a empresa.

Os que faltavam na segunda-feira eram os mais adictos do álcool. Com eles se fazia o trabalho de acompanhamento, supervisionado pelo serviço de saúde e por outros trabalhadores voluntários no domingo. A educação social foi feita tanto por meio de cartazes em toda a empresa como nas assembleias do sindicato, quando nos foi dada a oportunidade de explicitar o que era o alcoolismo no capitalismo chileno e as suas consequências para o trabalhador.

Além disso, foi organizada pelos estagiários uma ação coletiva durantes as comemorações da semana da pátria dos trabalhadores do Porto (fiestas patrias). Na primeira ocasião foi feita uma barraca de venda de bebidas não alcóolicas que teve pouco sucesso, mas que foi a mais concorrida depois de um ano de ação. Isso serviu para avaliar uma mudança de comportamento com a ação conjunta dos atores citados.

É importante salientar que a proposta articulou várias dimensões da ação de enfrentamento ao alcoolismo, envolvendo ação sindical, da saúde e da empresa, evidenciando-se a relação do alcoolismo com a alienação e o processo produtivo capitalista, além de ações voltadas para a saúde 3 .

\footnotetext{
${ }^{3}$ Quando preso politico em um barco de carga desativado, um dos jornais jogados no porão dizia que era acusado de promover o alcoolismo junto aos trabalhadores do Porto.
} 


\section{hevistg all pgutg}

\} RECONCEITUAÇÃO DO SERVIÇO SOCIAL - FALEIROS, V. P. \}

DOI: $10.12957 /$ REP.2017.32723

A relação teoria/prática se fazia não só no âmbito particular de cada estágio, mas na própria organização curricular. Participavam da prática de terreno estudantes e docentes durante quintas, sextas e sábados, quando se cancelavam as atividades de aula. Nas segundas, terças e quartas discutiam-se as práticas e as teorias em forma de seminários e oficinas. O aprendizado foi organizado completamente diferente do currículo tradicional, com integração teórico-prática, inclusive com a supervisão operacional na corresponsabilidade com a ação. Além disso, sua avaliação era compartilhada com os próprios trabalhadores. Os trabalhos de conclusão de curso traziam uma reflexão sistemática sobre a relação teoria-prática.

O currículo optativo também dava a oportunidade de aprofundamento de dimensões particulares da vida social dos trabalhadores do campo, da indústria e dos moradores urbanos, bem como das dimensões familiares, culturais e das políticas envolvidas nessas áreas. O estudante podia optar por estudar as políticas e dimensões específicas de uma ou de várias dessas áreas.

Esse movimento de mudança não deixou de trazer conflitos epistemológicos, pois colocou-se em questão uma visão e uma prática dominantes. Tratava-se de uma ação e de uma epistemologia que deslocavam a intervenção do Serviço Social para uma intervenção transformadora da ordem dominante, levando em conta a sua particularidade. Fazia uma crítica ao status quo da profissão e das metodologias tradicionais, focadas no Serviço Social de caso, Serviço Social de grupo e Serviço Social de comunidade.

O conflito se expressou na reação e nas críticas tanto de alas conservadoras, como de pessoas envolvidas com o próprio processo de reconceituação. Uma das críticas era de que a proposta não tinha possibilidades de ser operacionalizada. Assim, Ezequiel Ander-Egg (1984), em artigo publicado em 1972, afirmou que a reconceituação não tinha nada a ver com o próprio Serviço Social, tendo desenvolvido um discurso com categorias previamente estabelecidas pelo marxismo, o que significa apenas uma ilusão ou um discurso idealista com roupagem marxista. Trata-se de uma crítica, segundo ele, limitada a uma visão dogmática da reconceituação.

Por sua vez, Santos (1982) considera que nos anos 1970, como explosão de uma época, houve um metodologismo. No entanto, fez emergir a relação do Serviço Social com a ideologia, mas criando uma confusão entre trabalho ideológico e trabalho científico. A autora ressalta também que a crítica à ideologia pode contribuir para a separação do trabalho político em relação ao trabalho científico. Santos (1982) também critica o dualismo de separar trabalho institucional e trabalho político.

A caracterização do Movimento de Reconceituação apenas como atividade política ou própria de um mundo acadêmico tornou-se moeda corrente na consideração da reconceituação do Serviço Social. A dicotomia entre Academia e realidade não corresponde ao processo vivido na Escuela de Trabajo Social da UCV. Ao contrário, a inserção na realidade era uma 


\section{Revistg all paUtg}

\} RECONCEITUAÇÃO DO SERVIÇO SOCIAL - FALEIROS, V.P. \}

DOI: $10.12957 /$ REP.2017.32723

forma de participar também das mudanças das instituições. A segunda crítica era de que é impossível conciliar o trabalho social reconceituado com a prática institucional não corresponde ao que foi tentado na Escuela de Trabajo Social, como explicitado na experiência do Porto de Valparaíso.

\section{Considerações finais}

Como já assinalei alhures (FALEIROS, 2016), as críticas à politização do Serviço Social, no que se refere ao Movimento de Reconceituação, entendem que um trabalho profissional deve se pautar pela ótica da neutralidade. A crítica da neutralidade, por sua vez, traz incômodos, tanto epistemológicos quanto operacionais, ao conservadorismo presente nas práticas e instituições.

No livro Saber profissional e poder institucional (FALEIROS, 2015) aprofundo a dialética da relação da implicação entre saber e poder, pois em qualquer forma de se considerar o Serviço Social existe uma relação de poder. Nessa relação, as mediações vão sendo construídas epistemológicaestrategicamente como uma relação complexa de poder que envolve assimetrias e dominações, como também confrontos e contra-hegemonias.

A experiência da Escuela de Trabajo Social da UCV se situa na crítica das relações hegemônicas exercidas pelas instituições para manter o poder dominante. Dessa maneira, abre espaço para se pensar uma aliança do Serviço Social com os dominados e explorados em diferentes formas, por exemplo, no combate às violências contra a criança, a mulher, o negro e a comunidade LGBT, que formam parte de um bloco excluído da chamada normalidade dominante.

Tendo em vista a ênfase na luta de classes e nos movimentos operários, camponeses e urbanos, percebe-se que o Projeto da Escuela de Trabajo Social da UCV foi um processo que abriu a perspectiva de transformação das relações sociais de dominação pelo Serviço Social para tornar participantes e protagonistas da transformação os excluídos, explorados e dominados socialmente, seja em que relação de poder assimétrico estivessem.

A experiência contribuiu para elaborar uma nova epistemologia e para a construção do saber profissional de forma crítica e fundamentada, incorporando a análise marxista no constructo profissional e abrindo espaços para a crítica ao dogmatismo, à neutralidade, ao funcionalismo, ao positivismo, à acomodação e ao conservadorismo. 


\section{ReVistg all paUtg}

\} RECONCEITUAÇÃO DO SERVIÇO SOCIAL - FALEIROS, V. P. \}

DOI: $10.12957 /$ REP.2017.32723

\section{Referências}

ANDER-EGG, E.. Achaques y manias del servicio social reconceptualizado. Buenos Aires: Editorial Humanitas, 1984.

BASSO, L. et al. Transición al socialismo y experiência chilena. Santiago: Ceso; Ceren, 1972.

BURKE, P. Abertura: a nova história, seu passado e seu futuro. In: BURKE, P. (Org.). A escrita da história - novas perspectivas. São Paulo: Editora da Unesp, 1992.

FALEIROS, V. de P. Metodologia e ideologia do Trabalho Social. São Paulo: Cortez, 1981.

. O trabalho da política. São Paulo: Cortez, 2010.

. Violência institucional e violência nos locais de isolamento. In: CONSELHO FEDERAL DE PSICOLOGIA. Nenhuma forma de violência vale a pena. Brasília: CFP, 2011.

. Saber profissional e poder institucional. São Paulo: Cortez, 2015.

. Reconceituação: construção crítica e luta política e o paradigma da correlação de forças. In: RONDON, E. A.; ARAÚJO, S. S. M. de. Movimento de Reconceituação. História, memória e impactos nas políticas públicas. Rio de Janeiro: Autografia; Recife: Edupe, 2016.

FREIRE, PAULO. Pedagogia do oprimido.Rio de Janeiro, Paz e Terra, 1970. GARCÉS, J. Allende e l'expérience chilienne. Paris: Fondation Nationale des Sciences Politiques, 1976.

IDR. INSTITUTO DE DESENVOLVIMENTO DE RECURSOS HUMANOS. Que é o PED? - Relatório final de pesquisa. Brasília: IDR, 1998.

KOSIK, K. Dialectica de lo concreto. México: Grijalbo, 1967.

LIMA, B. A. Contribucion a la metodologia del Trabajo Social. Caracas: UCV - Facultad de Ciencias Económicas y Sociales, 1974.

MARX, K. Teses sobre Feuerbach. In MARX, K.; ENGELS, F. Ideologia alemã. Rio de Janeiro: Civilização Brasileira, 2007, p.611-613

MELUCCI, A. Por uma sociologia reflexiva - pesquisa qualitativa e cultura. Petrópolis: Vozes, 2005.

MÉSZÁROS, I. Estrutura social e formas de consciência II - A dialética da estrutura e da história. São Paulo: Boitempo, 2011.

PALMA, E. P. de; JOFRE, M. E.; FALEIROS, V. P.; QUIROZ, T.; LEIVA, C. Que és trabajo social? Valparaíso: Ediciones Universitarias de la Universidad Católica de Valparaíso, 1972. 


\section{ReVistg all paltg}

\} RECONCEITUAÇÃO DO SERVIÇO SOCIAL - FALEIROS, V. P. \}

DOI: $10.12957 /$ REP. 2017.32723

SALAZAR, M. C. Ciencia Social, Trabajo Social y modelos de intervencion. In: CELATS. Contribuciones a la metodologia del trabajo social. Lima: Celats, 1976.

SANTOS, L. L. Textos de Serviço Social. São Paulo: Cortez, 1982.

ZABALA, M. T. Metodo sin metodologia. Buenos Aires: Ecro, 1974.

DOI: 10.12957/rep.2017.32723

Recebido em 19 de agosto de 2017.

Aprovado para publicação em 04 de setembro de 2017.

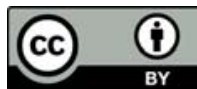

A Revista Em Pauta: Teoria Social e Realidade Contemporânea está licenciada com uma Licença Creative Commons Atribuição 4.0 Internacional. 